\title{
Robotic MaChining SimUlation USING A Simplified Multibody Model
}

\author{
Hoai Nam Huynh, Olivier Verlinden \& Edouard Rivière-Lorphèvre
}
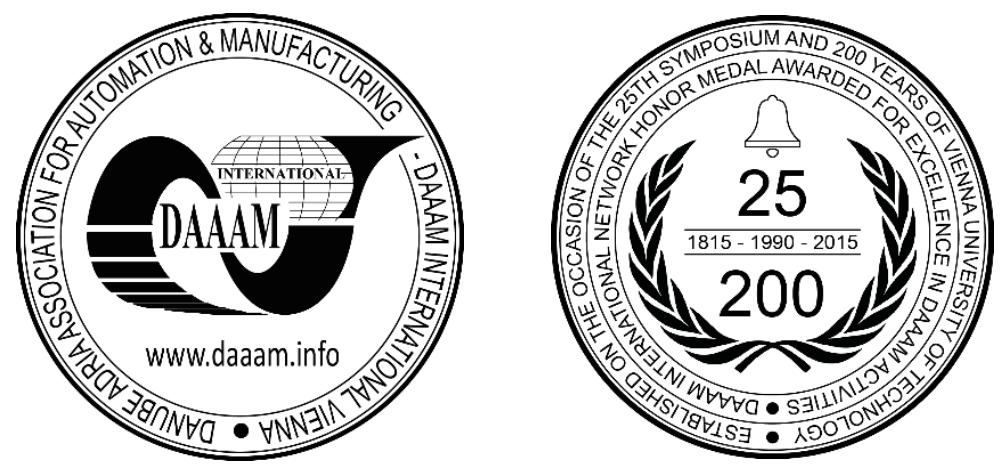

This Publication has to be referred as: Huynh, H[oai] N[am]; Verlinden, O[livier] \& Riviere-Lorphevre, E[douard] (2017). Robotic Machining Simulation using a Simplified Multibody Model, Proceedings of the 28th DAAAM International Symposium, pp.0885-0894, B. Katalinic (Ed.), Published by DAAAM International, ISBN 978-3-90273411-2, ISSN 1726-9679, Vienna, Austria

DOI: $10.2507 / 28$ th.daaam.proceedings.123

\begin{abstract}
Robotic machining is a promising manufacturing technology combining the agility of an industrial robot with the potential of a net shape process. Nowadays, robotic machining is springing up everywhere. A large number of companies attempt the conversion of their process using this technology, but without great success. Indeed, the material removal using a robot is very different from the conventional milling. Even though it is cheaper for a larger working envelope, the understanding of robotic process must be widened in order to overcome technological hurdles. Among them, the lack of stiffness at joints and the inherent low frequency structure are mainly accountable for the quality depletion of the machined workpiece. The simulation of an industrial process can be an interesting approach to better perceive the on-going phenomena during the machining phase. For this reason, a multibody modelling of a robot coupled with the simulation of milling was implemented. The robot was modelled as an anthropomorphic arm comprising 4 degrees of freedom and including the joint stiffness. Results were finally confronted with experimental data in terms of cutting forces, vibrations and roughness for which a good accordance could be observed.
\end{abstract}

Keywords: chatter; multibody; robotic machining; simulation; validation

\section{Introduction}

Robotic machining, which is the use of an industrial robot as a machine tool, is a manufacturing technique in demand these days. Many industrials are trying this relatively new technology by transposing their current process of material removal to the potential of robotics, but without great success. Although offering many advantages such as a lower cost for a larger workspace and a greater flexibility in terms of part accessibility, its development is held back due to several issues leading to the quality depletion of the final product. Limiting factors comprise the low stiffness of robot joints and their lack of accuracy. Furthermore, due to their low frequency structure, typically around 10 [Hz], industrial robots are more exposed to vibratory instabilities such as the chatter phenomenon. While there are two types of chatter named regenerative chatter and mode coupling chatter, Pan Z. et al. [1] found that the latter was the dominant source of vibration in robotic machining. Above all, chatter phenomenon must be avoided as it leads to a sharp increase in cutting forces and vibrations wrecking the surface finish of the workpiece and sometimes conducting to tool breakage. 
Barnfather J.D. et al. [2] also stated that a barrier to its deployment is the dimensional errors coming from the low dynamic stiffness and their low resistance to machining forces. Dumas et al. draw attention on the fact that the low joint stiffness affects the surface finish [3]. Geometrical errors in robot links and joints cause assembly misalignments and affect the positioning accuracy of the end-effector [4]. In other words, issues commonly found in conventional machining such as the tool deflection, the backlash at joints and wear are magnified due to the less rigid structure [5].

Yet robotic machining is consequently bound to operations requiring low cutting forces in order to avoid the aforementioned issues. Its field of applications especially concerns finishing operations such as grinding, polishing, deburring, drilling, sanding, cutting and the milling of soft materials, for example, plastic, wood, foam, aluminium and even steel when small layers are removed. Different industrial sectors benefit from robotic machining keeping in mind that they will take full advantage of the technology when machining large workpieces. It is certainly the case of aerospace for the polishing of turbine blades and the drilling of wing segments and in foundries for the deburring of cast parts (Fig. 1) $[6]$.

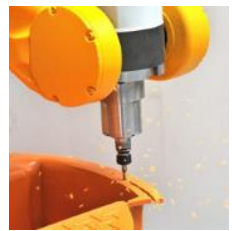

a) Plastics

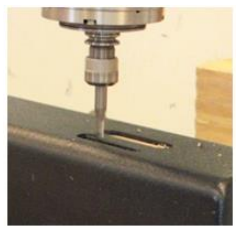

b) Carbon-fiber

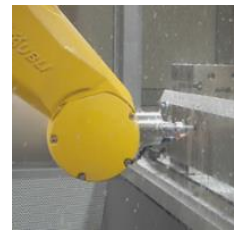

c) Aluminium

Fig. 1. Applications in robotic machining

Even though industrial robots will not replace conventional machine tools in all machining operations because of their lack of stiffness and precision, research is conducted in order to better understand such a process. On-going research focusses on the development of indicators pointing stiffer robot configurations, the optimal placement of the workpiece with respect to the robot, the implementation of calibration procedure to improve part quality, the installation of extra actuator to compensate robot positioning error, the improvement of existing controllers, the creation of off-line compensation methods, etc.

For instance, Ilyukhin Y.V. proposed a new control structure ensuring high-performance machining [7]. Their algorithm generated corrected values for the velocity path taking into account the currents in the windings of all servomotors. As a result, the milling tool followed continuous path without overheating and overloading the drives. Klimchik A. et al. ranked five industrial robots according to a developed approach based on the circularity norm that evaluates the contortion degree of a benchmark circle [8]. This industry-oriented methodology allows its user identifying which robot will offer the best machining accuracy on the basis of a model. The method was validated experimentally and proved to be in good agreement with the theoretical model.

Finally, Bauer J. et al aimed at developing a strategy to improve the accuracy in robotic machining by prediction and offline compensation of path deviations on the basis of the ideal cutting forces and offset mirroring [9]. For this purpose, they adapted a cutting force model and applied it for industrial robots in order to perform simulations. The robot motion was computed using the Newton-Euler formulation. Both sub-models were first tested separately before their coupling to simulate the machine process interaction. Milling experiments were eventually achieved to confirm the compensation concept.

This paper is also related to the simulation of robotic machining with process interaction but rather targeted to the model validation. A simplified multibody model of an existing robot was built and coupled with a milling routine in order to simulate the whole process. Section 2 is dedicated to the presentation of the robot and the cutting force models, followed by their coupling. Section 3 describes the two milling operations studied in this paper as well as the cutting parameters employed to replicate milling experiments. The comparison of the results is based on the analysis of the cutting force amplitudes, the vibrations and the lateral roughness of the machined workpiece in section 4 . The last section will draw the final summary and future work.

\section{Robotic machining modelling}

In order to develop a simulation environment of robotic machining, the industrial robot and the milling process should first be modelled separately and then coupled together. The robot was modelled using the multibody approach while cutting forces were computed according to a macroscopic representation of the material removal. Both models were programmed in $\mathrm{C}++$ and were coupled in one single simulation environment of robotic machining.

\subsection{Robot modelling}

As milling tests were performed using a serial 6-dof industrial robot from Stäubli, the robot model was naturally inspired by its geometrical dimensions. The TX200 model from Stäubli is a heavy payload robot featuring a nominal load 
capacity of $1000[\mathrm{~N}]$, a reach of 2194 [mm] and a repeatability of \pm 0.06 [mm]. Its stiffness is more than sufficient to withstand the cutting forces as the machined part quality can attest. The aim was to simulate the dynamic behaviour of the robotic arm in a simplified way.

The anthropomorphic arm was simplified into a 4-axis manipulator whose motion can span a $3 \mathrm{D}$ envelope. The simplification was considered to alleviate the computational load of the inverse kinematic algorithm and to keep a simple model while being apt to represent the main trend in robotic machining. Figure 2 presents the real industrial robot comprising its 6 degrees of freedom (DOF) and its simplified model with 4 DOFs and 5 bodies. As the robot was intended to machine a workpiece following a $2 \mathrm{D}^{1 / 2}$ path, the motion of the last link belonging to the simplified model was such that the latter remains in vertical position.

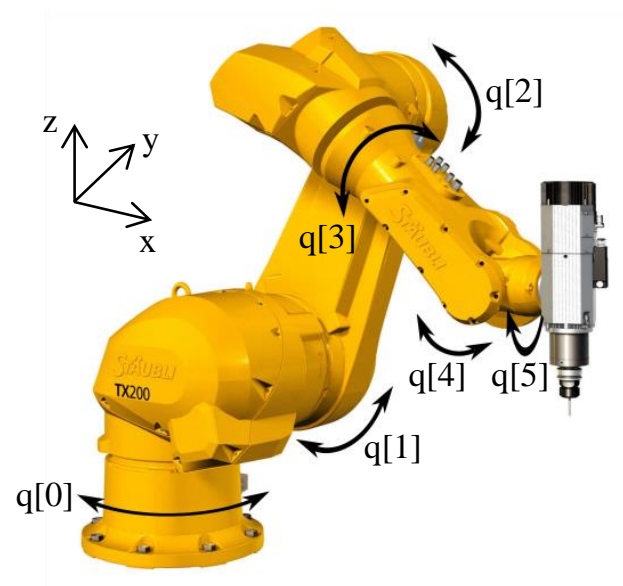

a) Stäubli TX200

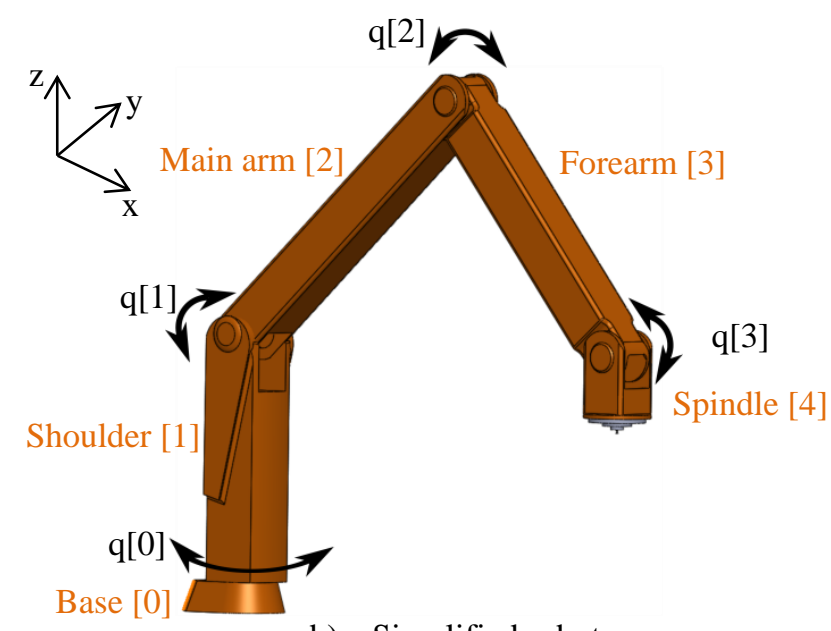

b) Simplified robot

Fig. 2. Simplified robot modelling

In order to define the mass and inertia properties of each body pertaining to the simplified model, it was necessary to know the mass distribution of the real robot components. Nevertheless, such data are not directly available from the robot manufacturer. Only the total mass of the Stäubli robot can be retrieved and equals 981 [kg]. To better reproduce the behaviour of the industrial robot with the simplified model, it was therefore essential to distribute the total mass amongst the five bodies, respectively named the base, the shoulder, the main arm, the forearm and the spindle. For that purpose, two considerations had to be taken into account:

- The mass distribution of the real robot is similar to its volume distribution. CAD designs of the robotic arm are provided by the robot manufacturer but the mass of each component cannot be inferred as the virtual shapes are not hollowed. Consequently, shapes can only give information about their volume.

- The shoulder of the robot (body [1]) is naturally heavier than its other components as it embeds the two main motors for joints 1 and 2 .

As a result, it was decided to distribute the mass of the robot according to the volume of each of its component. Concerning the identification of their moment of inertia, each robot part was simplified into a rectangular parallelepiped with an equivalent volume. Table 1. displays a synopsis of the mass and moment of inertia for each part of the simplified robot. It was not necessary to define the moments of inertia for the base (body [0]) as it does not intervene in the motion of the robot.

\begin{tabular}{|c|c|c|c|c|c|}
\hline Body & Mass [kg] & Ixx [kg.m²] & Iyy [kg.m²] & Izz [kg.m $\left.{ }^{2}\right]$ & Length [m] \\
\hline Base [0] & 183 & 1 & 1 & 1 & Lg: 0.1 \\
\hline Shoulder [1] & 342 & 18.044 & 29.213 & 30.014 & L1: 0.65 \\
\hline Main arm [2] & 243 & 35.033 & 37.463 & 4.050 & L2: 0.95 \\
\hline Forearm [3] & 202 & 5.507 & 5.507 & 4.547 & L3: 0.85 \\
\hline Spindle [4] & 11 & 0.103 & 0.103 & 0.041 & L4: 0.2 \\
\hline
\end{tabular}

Table 1. Mass and moments of inertia of the simplified robot components

On the basis of the inertia properties and the positions of each centre of mass, it was then possible to model the simplified robot as a multibody system. To help with this modelling, the Theoretical Mechanics, Dynamics and Vibration Department of the University of Mons (Belgium) developed a multibody framework called EasyDyn allowing the 
dynamic simulation of mechanical systems [10]. Initially created for teaching purposes, it was successfully used in several Master's and $\mathrm{PhD}$ theses and is available for free on the Internet.

EasyDyn offers its user the possibility to solve problems represented by second-order differential equations and, more particularly, the dynamic behaviour of mechanical multibody systems. The approach currently implemented is based on the minimal coordinates for the choice of the configuration parameters q defining the motion of the bodies. The kinematics of all bodies is provided by the user through homogeneous transformation matrices $\mathrm{T}$ function of the chosen configuration parameters as far as they are independent. The number of configuration parameters is consequently equivalent to the number of degrees of freedom. The expressions of position and orientation of each body i comes from its transformation homogeneous matrix $\mathrm{T}_{0, \mathrm{i}}$ considered at their centre of mass. The latter is then symbolically derived in order to get the expressions of velocities and accelerations $\left(\mathrm{T}_{0, \mathrm{i}}\right.$ gives the position and orientation of the frame attached to centre of mass of body $i$ with respect to a global reference frame 0) (Fig. 3). The kinematics of each body i is accordingly a function of $\mathrm{q}$ and its time-derivatives $\dot{q}$ and $\ddot{q}$. Aside from the kinematics, the user may also apply forces on each body.

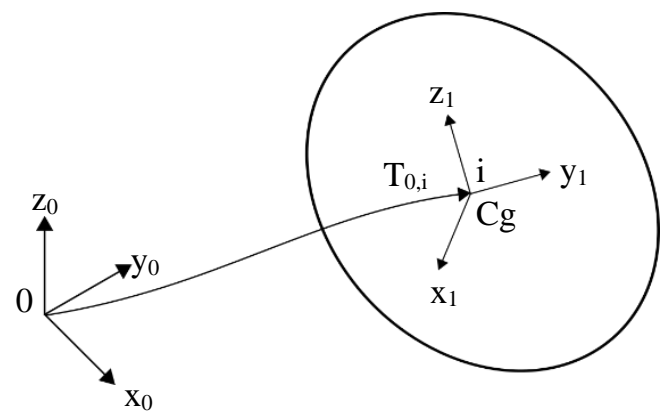

Fig. 3. Frame situation of body i with respect to the global reference frame 0

As the simplified robot model comprised five bodies, its kinematic model involved the definition of five homogeneous transformation matrices expressed as follows:

$\mathrm{T}_{0}=\operatorname{Tdisp}(0,0,-\mathrm{Lg} / 2)$

$\mathrm{T}_{0,1}=\operatorname{Trotz}(\mathrm{q}[0]) \times \operatorname{Tdisp}(0,0, \mathrm{~L} 1 / 2)$

$\mathrm{T}_{1,2}=\operatorname{Tdisp}(0,0, \mathrm{~L} 1 / 2) \times \operatorname{Troty}(\mathrm{q}[1]) \times \operatorname{Tdisp}(0,0, \mathrm{~L} 2 / 2)$

$\mathrm{T}_{2,3}=\operatorname{Tdisp}(0,0, \mathrm{~L} 2 / 2) \times \operatorname{Troty}(\mathrm{q}[2]) \times \operatorname{Tdisp}(0,0, \mathrm{~L} 3 / 2)$

$\mathrm{T}_{3,4}=\operatorname{Tdisp}(0,0, \mathrm{~L} 3 / 2) \times \operatorname{Troty}(\mathrm{q}[3]) \times \operatorname{Tdisp}(0,0, \mathrm{~L} 4 / 2)$

where

- $\operatorname{Tdisp}(\mathrm{x}, \mathrm{y}, \mathrm{z})$ represents a homogeneous transformation matrix corresponding to a displacement without rotation by coordinates $\mathrm{x}, \mathrm{y}$ and $\mathrm{z}$;

- $\operatorname{Troty}(\gamma)$ or $\operatorname{Trotz}(\gamma)$ represents a homogeneous transformation matrix corresponding to a rotation around y- or z-axis respectively of an angle $\gamma$.

The $\mathrm{n}_{\mathrm{cp}}$ equations of motion were then built according to the given kinematics involving the $\mathrm{n}_{\mathrm{cp}}$ configuration parameters and the applied forces on the $\mathrm{n}_{\mathrm{B}}$ bodies. Their form derives from the application of the d'Alembert's principle:

$$
\sum_{i=1}^{n_{B}}\left[d^{i, j} \cdot\left(\vec{R}_{i}-m_{i} \vec{a}_{i}\right)+\theta^{i, j} \cdot\left(\vec{M}_{G_{i}}-\Phi_{G_{i}} \overrightarrow{\mathbf{\boldsymbol { \omega }}}_{i}-\overrightarrow{\boldsymbol{\omega}}_{\mathbf{i}} \times \Phi_{G_{i}} \overrightarrow{\mathbf{\omega}}_{i}\right)\right]=0 \quad \mathrm{j}=1, \mathrm{n}_{\mathrm{cp}}
$$

- $m_{i}$ is the mass of body $\mathrm{i}$;

- $\Phi_{G_{i}}$ is the inertia tensor of body $\mathrm{i}$;

- $\overrightarrow{R_{i}}$ is the resultant force of all applied forces acting on body $\mathrm{i}$;

- $\vec{M}_{G_{i}}$ is the resultant moment at the centre of mass $G_{i}$ of all applied forces acting on body $\mathrm{i}$;

- $\vec{v}_{i}$ is the velocity of the center of mass of body $i$;

- $\vec{\omega}_{i}$ is the rotational velocity of body $\mathrm{i}$;

- $d^{i, j}$ is the partial contribution of $\overrightarrow{\dot{q}}_{j}$ in the translational velocity of body i: $\vec{v}_{i}=\sum_{j=1}^{n_{c p}} d^{i, j} \cdot \vec{q}_{j}$;

- $\theta^{i, j}$ is the partial contribution of $\vec{q}_{j}$ in the rotational velocity of body i: $\overrightarrow{\omega_{i}}=\sum_{j=1}^{n_{c p}} \theta^{i, j} \cdot \overrightarrow{\dot{q}_{j}}$.

Once built, the equations of motion were integrated according to the Newmark integration method, the parameters corresponding to the standard Newmark 1/4. 
The robot modelling would not have been complete without the introduction of joint stiffness, being the main weakness of industrial robots. The component bringing such flexibility is mainly the gearbox of each motor which was modelled as a rotational spring along with a damper located between each link (Fig. 4).

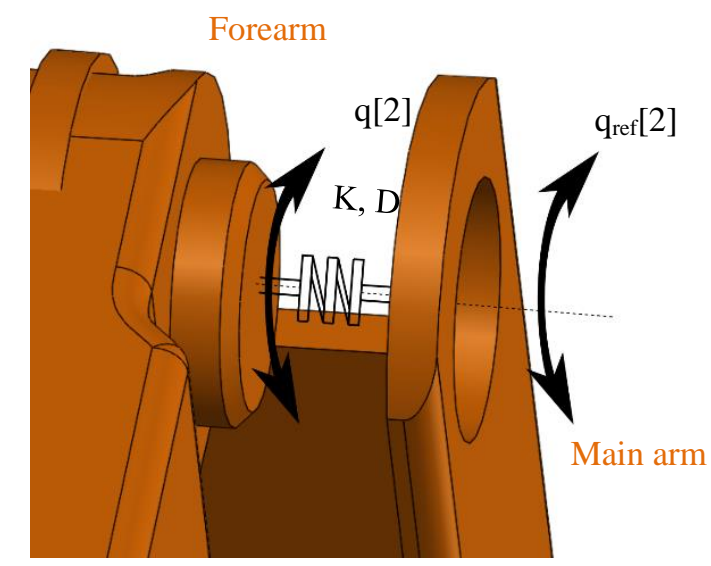

Fig. 4. Joint flexibility modelled as a spring $\mathrm{K}$ and a damper $\mathrm{D}$

The torque applied at joint $i+1$ simply results from the difference between the reference position $\mathrm{q}_{\text {ref }}[\mathrm{i}]$ at joint $\mathrm{i}$, computed by the inverse kinematic algorithm, and the real joint position $q[i]$ after the spring and the damper (7). The reaction torque is applied at joint $\mathrm{i}(8)$.

$$
\begin{aligned}
& M_{i+1}=K_{i} \cdot\left(q_{r e f}[i]-q[i]\right)-D_{i} \cdot \dot{q}_{i} \\
& M_{i}=K_{i} \cdot\left(q_{r e f}[i]-q[i]\right)-D_{i} \cdot \dot{q}_{i}
\end{aligned}
$$

The values of stiffness were picked up from an article presenting a methodology to identify the joint stiffness experimentally. The studied industrial robot (Kuka KR240-2) was also very similar in terms of size [3]. Joint damping coefficients were harder to find. In the $\mathrm{PhD}$ thesis of Oueslati M., the damping coefficient of joint 2 was experimentally identified for the Stäubli RX170B robot [11]. It was deduced from the exponential decay of the vibration signal measured on the position of the second link when subjected to position step. However, the estimated value seemed quite high $\left(D_{\text {ref }}=4960\right.$ [N.m.s/rad]) and lead to purely real poles characterised by a damping coefficient of $100 \%$. In order to find more realistic values, the damping coefficient was rescaled as a function of the squared root of the ratio involving $\mathrm{K}_{\text {ref }}$ (provided in [14]) and the stiffness to associate, as indicated by equation (9). Table 2 finally provides the stiffness and damping values used for the simplified robot model. Additionally, a torque compensation for the gravity was applied at joints 1 and 2 as a function of the mass of the links following them.

$$
\frac{D_{i}}{D_{\text {ref }}}=\sqrt{\frac{K_{i}}{K_{\text {ref }}}}
$$

\begin{tabular}{|lc|c|c|c|c|}
\hline & & Joint 1 & Joint 2 & Joint 3 & Joint 4 \\
\hline Stiffness [N.m/rad] & K & $3.8 \cdot 10^{6}$ & $6.6 \cdot 10^{6}$ & $3.9 \cdot 10^{6}$ & $0.66 \cdot 10^{6}$ \\
\hline Damping [N.m.s/rad] D & 1057.2 & 1393.3 & 1071.0 & 440.6 \\
\hline
\end{tabular}

Table 2. Joint stiffness and damping

\subsection{Machining model}

In order to simulate the whole process of robotic machining, the machining process has to be modelled accurately to correctly predict the interaction between the workpiece and the mechanical system. Although microscopic and mesoscopic models exist, these methods require large simulation time that industrials can rarely afford. A fair compromise is to rely on macroscopic approaches combining a mechanistic model of the cutting forces, a numerical model of the dynamic response of the mechanical system and a geometrical representation of the machined workpiece.

The machining modelling was handled by an in-house milling routine, called DyStaMill for "Dynamic Stability of Milling operations" that implements a macroscopic model of material removal. It was also developed at the University of Mons by Rivière-Lorphèvre E. during his PhD thesis about the stability of high-speed milling [12]. It was first created to study the stability of machine tool for operations generating $2 \mathrm{D}^{1 / 2}$ shapes such as slotting, contouring, pocketing or face milling. In a practical way, dynamic simulation of milling involves three different features: 
1. The prediction of the cutting forces;

2. The modelling of the workpiece;

3. A representation of the mechanical system which is in this case the aforementioned robot model.

The representation of the machined surface has to be as accurate as possible for being able to predict the milling instabilities. Indeed, it is of great importance when chatter phenomenon occurs as it is a regenerative process appearing when the tool removes material from a previously machined surface [13]. In DyStaMill, the update of the workpiece is inspired from the "eraser of matter" model proposed by G. Peigné [14]. The part is divided into superimposed slices and each $2 \mathrm{D}$ contour is approximated by a succession of straight segments. The end mill is also discretised into superimposed discs along its revolving axis in such a way that each of them interacts with one $2 \mathrm{D}$ contour. The motion of the cutting edges is also considered in the model and an intersection procedure is set up to compute the chip thickness. It is assumed that the displacements of the tool lie in a plane thus yielding to a $2 \mathrm{D}^{1 / 2}$ workpiece representation (Fig. 5).

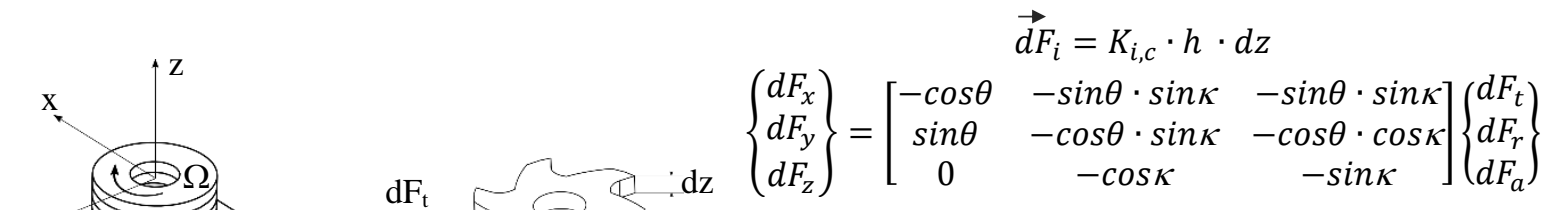

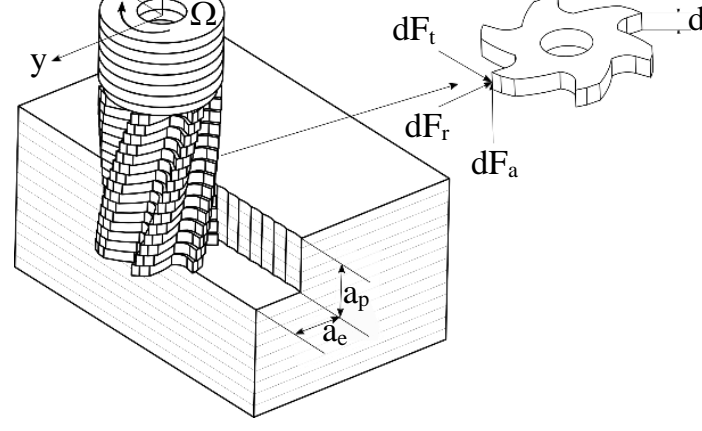

- $\mathrm{a}_{\mathrm{e}}$ and $\mathrm{a}_{\mathrm{p}}$ are the radial and axial depths of cut respectively $[\mathrm{mm}]$;

- $d \vec{F}_{\text {i:a,r,t }}$ is the local cutting force element in the axial, radial or tangential direction $[\mathrm{N}]$;

- $K_{\mathrm{i}, \mathrm{c}}$ is the cutting force coefficient $\left[\mathrm{N} / \mathrm{m}^{2}\right]$;

- $h$ is the chip thickness [mm];

- $d z$ is the height of an infinitesimal disc [mm];

- $\Omega$ is the angular speed of the spindle [RPM];

- $\theta$ and $\kappa$ are the rotation angle of the cutting edge and the angle orienting the radial direction [rad];

Fig. 5. Machining model

- $d \vec{F}_{x, y, z}$ is the cutting force element projected into the global reference frame $[\mathrm{N}]$.

On the other hand, the computation of the cutting forces is based on a mechanistic model. This kind of model allows the prediction of the cutting forces from a given tool/ material couple using simple analytical laws. The latter assumes that the cutting force is proportional to the undeformed chip cross section. In DyStaMill, the popular model from Altintas Y. is used (10) to compute the cutting forces locally along the axial $d F_{a}$, radial $d F_{r}$ and tangential $d F_{t}$ directions at the cutting edges from the undeformed chip thickness $h$ [15]. The local cutting forces are then projected into the global reference frame on the basis of cutting angles (11). Cutting force coefficients $K_{i, c}$ can be determined experimentally from slotting operations whose measured signals are processed by an inverse analysis [16].

\subsection{Coupling of the two sub-models}

With the objective of simulating the whole process of robotic machining, the DyStaMill routine was coupled and integrated into the multibody framework EasyDyn. The coupled environment was validated on machine tool test cases [17], [18]. Figure 6 presents the interactions between the milling routine and the multibody framework. The first step consists in entering the inertia properties of each body and the simulation parameters for the milling phase such as the tool diameter $\emptyset_{\text {tool }}$, the number of edges, the radial and axial depths of cut, the spindle angular speed and the cutting coefficients. The complete kinematics of the mechanical system can then be derived from the homogeneous transformation matrices. On the basis of the prediction of the tool centre point position at the end of the time step, it is possible for DyStaMill to predict the size of the chip thanks to intersection functions looking for the meeting point between the workpiece and the cutting edge. From then, the global cutting forces can be inferred for being considered into the integration procedure as force elements. Once the configuration parameters have been recomputed, the workpiece geometry is updated before resuming the procedure.

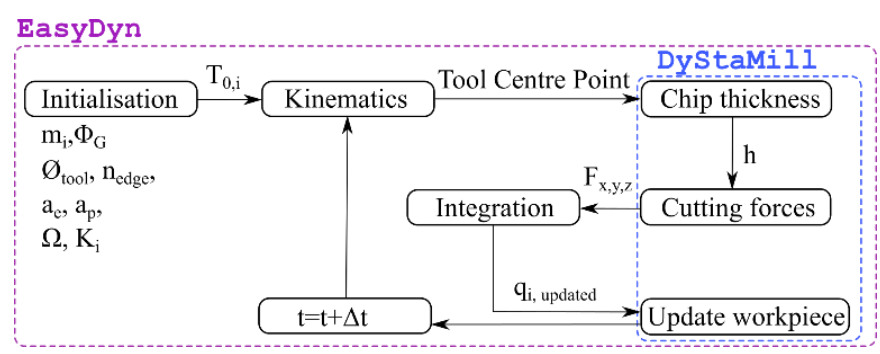

Fig. 6. Robotic machining simulation environment 


\section{Definition of the milling operations}

This brief section lays out the two considered milling operations that the robot achieved within the robotic machining simulation environment. The cutting parameters adopted in this simulation context are also presented.

\subsection{Longitudinal and transversal milling pass}

As announced, the robot performed two milling operations in such a way that its end-effector remained in a horizontal plane, ending up with two shouldering operations. One shoulder was machined in the expansion direction of the arm (longitudinal pass, $x$-axis) while the other one was made perpendicular to the former one (transversal pass, y-axis) (Fig. 7). The reference position of each joint $\mathrm{q}_{\mathrm{ref}}[\mathrm{i}]$ was computed on the basis of an inverse kinematic algorithm simply yielding in the resolution of two triangles. As a result, the end effector position set point was given in terms of $\mathrm{x}$ and $\mathrm{y}$ coordinates and translated into joint coordinates, assuming that the $\mathrm{z}$ coordinate was fixed. The motion of the end effector was settled so that its velocity increased smoothly from a null speed to the desired feed rate. Figure 8 shows the followed velocity profile by the end effector, it amounted to successively apply a constant jerk for 0.4 [s], a constant acceleration for 0.2 [s] and the reverse jerk for 0.4 [s] before reaching the desired feed rate in 1.0 [s].

It should also be mentioned that to speed up the computation, two integration time steps, in terms of duration, were chosen. The first one was set to $\Delta \mathrm{t}=0.001$ [s] while the end effector stabilises around the desired feed rate. Then, it was necessary to strongly reduce the integration time step to take into account the machining phase. As a matter of fact, the workpiece geometry has to be updated at least 30 times per tool revolution. For the present simulation, the machined surface was kept up-to-date 100 times per tool revolution which turned out to be $\Delta \mathrm{t}=3.21 \times 10^{-5}$ [s]. To sum up, the endeffector accelerated outside the workpiece before stabilising at the desired speed and entering into the workpiece.

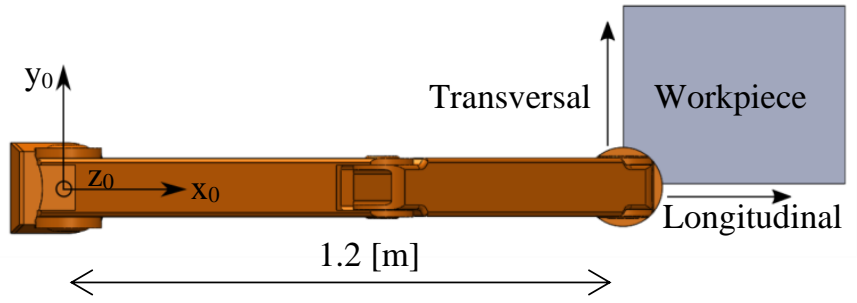

Fig. 7. Top view of the milling operations

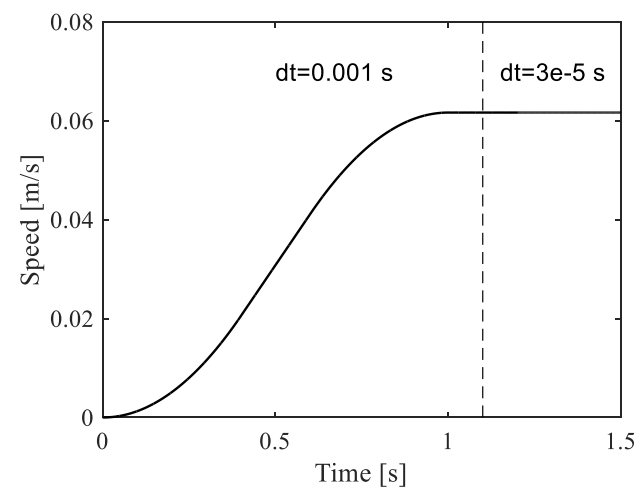

Fig. 8. End effector velocity profile

\subsection{Cutting parameters}

Cutting parameters were chosen according to real robotic machining tests which were performed with a Stäubli TX200 robot (Table 3). Four different milling experiments were accomplished in an aluminium plate 6060 T6:

1. Longitudinal pass in down-milling;

2. Longitudinal pass in up-milling;

3. Transversal pass in down-milling (Fig. 9);

4. Transversal pass in up-milling.

\begin{tabular}{|c|l|c|}
\hline Solid Tool & Diameter & $10[\mathrm{~mm}]$ \\
\hline & Nb. of teeth & 2 \\
\hline & Helix angle & $30^{\circ}$ \\
\hline & Variable tooth pitch & $170^{\circ}-190^{\circ}$ \\
\hline \multirow{2}{*}{$\begin{array}{c}\text { Milling } \\
\text { operation }\end{array}$} & Radial depth of cut $\left(\mathbf{a}_{\mathbf{e}}\right)$ & $4[\mathrm{~mm}]$ \\
\cline { 2 - 3 } & Axial depth of cut $\left(\mathbf{a}_{\mathbf{p}}\right)$ & $1.6[\mathrm{~mm}]$ \\
\hline & Spindle speed & $18700[\mathrm{RPM}]$ \\
\hline & Feed rate & $3700 \mathrm{~mm} / \mathrm{min}$ \\
\hline & Cutting coefficients $\left(\mathbf{K}_{\mathbf{t c}}, \mathbf{K}_{\mathbf{r c}}\right)$ & $661.513,253.458[\mathrm{MPa}]$ \\
\hline
\end{tabular}

Table 3. Cutting parameters

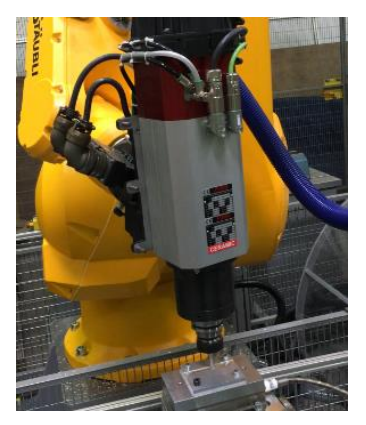

Fig. 9. Robotic machining tests 
Cutting forces $F_{x}, F_{y}$ and $F_{z}$ were recorded thanks to a force sensor located under the workpiece and a triaxial accelerometer was in charge of the vibration signal acquisition. Data were sampled at 10,000 [Hz]. Cutting force data were already exploited in order to extract the cutting coefficients $K_{\mathrm{tc}}$ and $\mathrm{K}_{\mathrm{rc}}$ from an inverse analysis. $\mathrm{K}_{\mathrm{ac}}$ was not identified as the axial signal is often of a lesser quality.

\section{Comparison with experiment}

With the robotic machining simulation environment on the one hand and experimental data available on the other hand, it is now possible to compare the obtained results and to comment on the modelling quality to replicate real data. Results are compared in terms of cutting forces, vibrations and lateral roughness of the machined part.

\subsection{Cutting forces}

First of all, cutting forces were compared with experimental data within the context of the four experiments described in section 3.2. Figures 10 to 13 superimpose simulation (plain lines) and experimental (dashed lines) data over two tool revolutions for cutting forces $F_{x}$ (in blue) and $F_{y}$ (in red) measured at tooltip and projected in the global reference frame ( $\mathrm{F}_{\mathrm{z}}$ signal is not shown since $\mathrm{K}_{\mathrm{ac}}$ couldn't be identified properly).

Overall, the simulated cutting forces followed the experimental signals in steady state. They were well correlated in terms of amplitude which meant that the cutting coefficients were well identified. Their periodicity was also in concordance with the set spindle speed of 18700 [RPM]. As expected, it can be observed that the signal perpendicular to the feed direction $\left(F_{y}\right)$ is always higher since the tooth enters normally to the material surface. Furthermore, given that the end mill featured a variable tooth pitch $\left(170^{\circ} \mid 190^{\circ}\right)$, cutting force amplitudes alternated between high and lower peaks as it was the case for experimental data.

As shown in Fig. 10 and 11, $F_{y}$ signal was slightly more noisy but respected the theoretical trend. Lastly, experimental peaks along the $\mathrm{x}$-axis were slightly higher than predicted, thus resulting in a falling edge occurring a bit later.

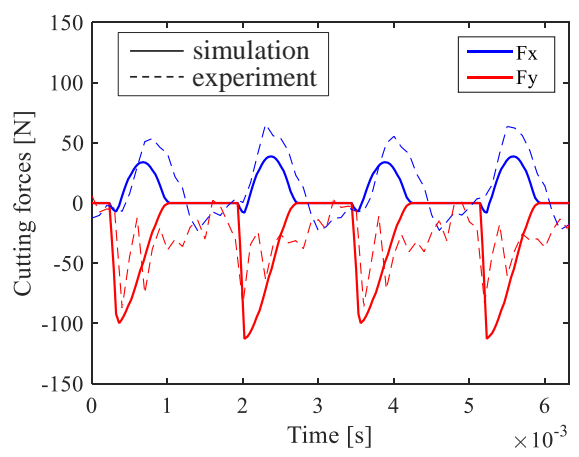

Fig. 10. Longitudinal pass in down-milling

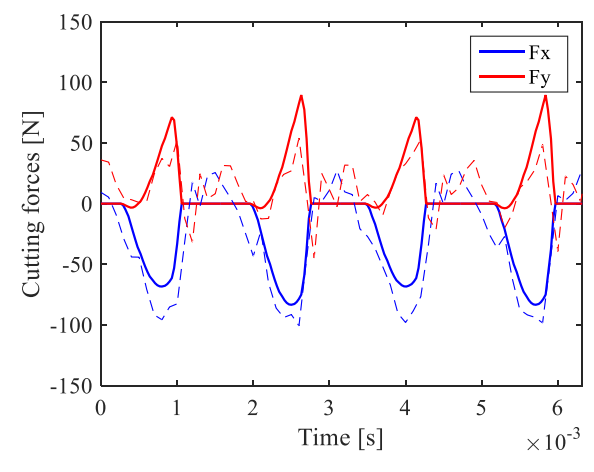

Fig. 11. Longitudinal pass in up-milling

As for transversal tests (Fig. 12 and 13), simulated cutting force $F_{y}$ correlated quite well its experimental counterpart in terms of amplitude and periodicity. Nevertheless, its falling edge still appeared before the experimental fall. Concerning cutting force $F_{x}$, experimental signal was very noisy and it was difficult to notice the analogy. Amplitudes were still coherent.

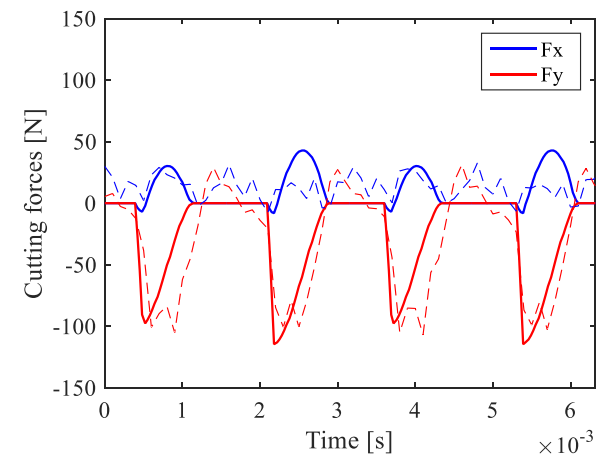

Fig. 12. Transversal pass in down-milling

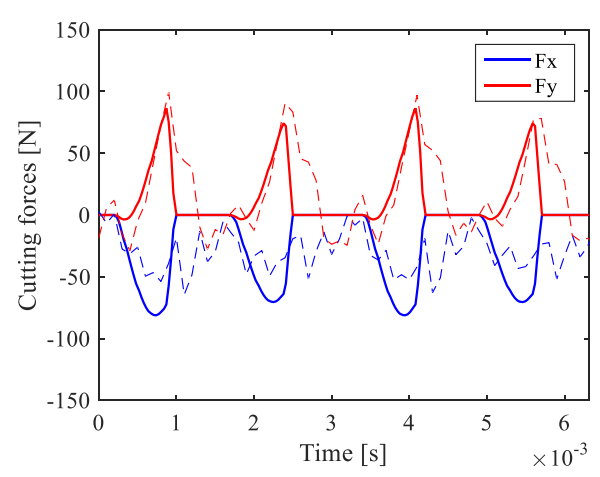

Fig. 13. Transversal pass in up-milling 


\subsection{Vibrations}

In terms of vibrations, if signals along the feed direction were compared, again the steady state amplitudes correlated experimental data (Fig. 14). However, such statement could not be drawn for vibration signals perpendicular to the feed direction: the simulated vibration signals were much lower. This effect might be partially related to the fact that the simplified robot model did not take into account that the links of the real robot are not in the same plane (Fig. 2.a).

A frequential analysis on the cutting force signals was also carried out and revealed peaks and harmonics at frequencies corresponding to the spindle rotational speed $(311.67[\mathrm{~Hz}])$ and to the tooth passing frequency $(623.33[\mathrm{~Hz}])(\mathrm{Fig} .15)$.

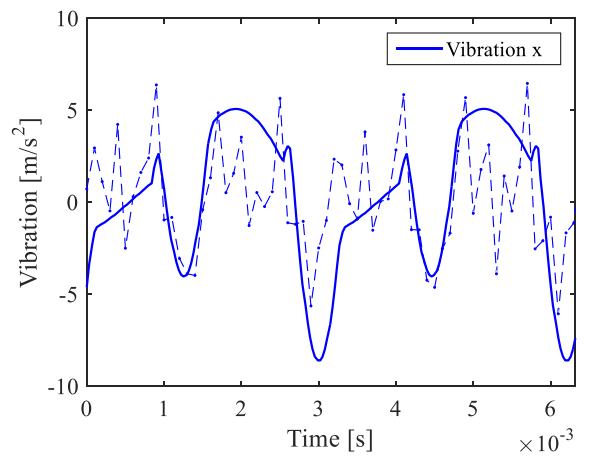

Fig. 14. Longitudinal pass in down-milling

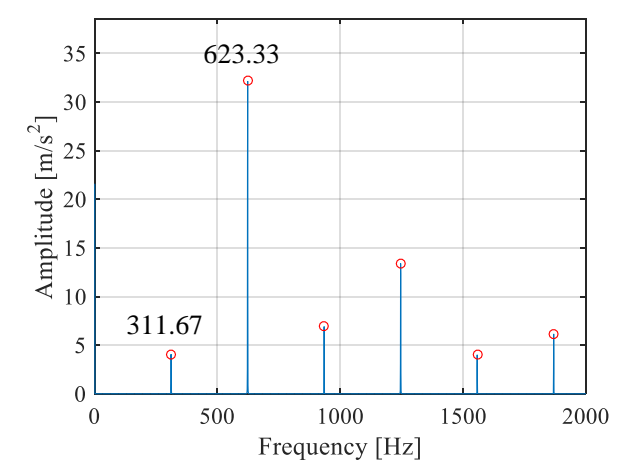

Fig. 15: Spectral analysis on the simulated signal

\subsection{Lateral roughness}

The virtual machined workpiece was compared with the real finished product in terms of lateral roughness. Before presenting the roughness results, it should be noted that the tool deviation in relation to the nominal value $\left(a_{e}=4[\mathrm{~mm}]\right)$ was around $10[\mu \mathrm{m}]$ in any simulation. Although this deviation is difficult to evaluate on the real part, no large offsets were detected which tend to support that the order of magnitude was well estimated (Fig. 16).

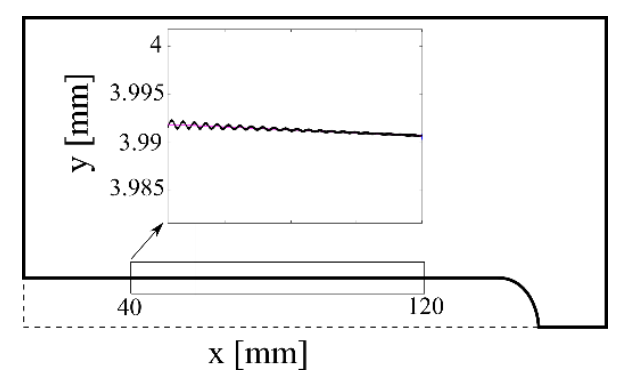

Fig. 16. End mill deviation (down-milling)

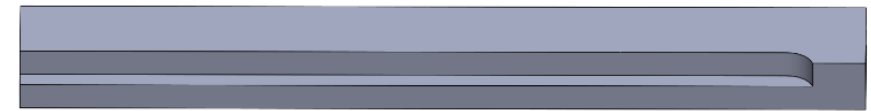

Simulation: $\mathrm{R}_{\mathrm{a}}: 0.32, \mathrm{R}_{\mathrm{t}}: 1.98, \mathrm{R}_{\mathrm{q}}: 0.39[\mu \mathrm{m}]$ (Down-milling)

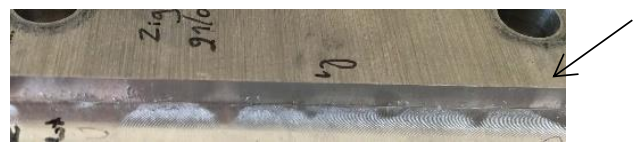

Experiment: $\mathrm{R}_{\mathrm{a}}: 0.36, \mathrm{R}_{\mathrm{t}}: 2.0, \mathrm{R}_{\mathrm{q}}: 0.43$ [ $\left.\mu \mathrm{m}\right]$ (Down-milling)

Fig. 17. Roughness comparison

At a first glance, according to Fig. 17, roughness evaluated on experimental and simulated data is almost equivalent. Arithmetic roughness $R_{a}$, quadratic roughness $R_{q}$ and total roughness $R_{t}$ were computed on the basis of their classical formulae. Both the simulation values and the real data shown on the figure originate from the longitudinal pass in downmilling. In robotic machining, the latter constitutes the preferential cutting condition. An inspection of real machined parts revealed that up-milling tests should be prohibited in robotic machining as it leads to higher cutting forces and the pull-out of the surface material resulting in a sharp increase of roughness. The experimental roughness values retrieved for the transversal pass in down-milling were slightly higher but the surface finish was still acceptable. As the simplified modelling was not able to capture the roughness quality depletion in up-milling, the model should be refined in future work.

\section{Conclusion}

Robotic machining is a growing technology but investigations still need to be conducted to better understand the ongoing phenomena while milling. The proof of concept subsists in the simulation of the whole robotic machining process. Once validated, the model should be able to predict in advance for which set of cutting parameters the machining will reach an optimum in terms of part quality, productivity and stability.

Even though simplistic, this work presented a simplified modelling of robotic machining. A 6-axis robot was transposed and modelled as a 4-axis anthropomorphic arm using the multibody approach and coupled with a milling routine. Four different machining tests were accomplished and compared with experimental data. Results showed a good accordance in terms of cutting force and vibration amplitudes, roughness and tool deviation. More specifically, cutting 
forces were well correlated. Vibration amplitudes along the feed direction were correctly approximated whereas signals found in the perpendicular direction were too low probably because of the geometrical approximations of the robot model. Roughness and tool deviation were only in accordance with real data for a longitudinal pass in down-milling. The simulation model should therefore be revised appropriately even though it was already able to capture the overall trends.

Before developing a simulation environment comprising a 6-axis robot, it would be interesting to check whether the current model is able to predict unstable milling conditions. Future work will therefore focus on the possibility to define stability lobes commonly used in machining to identify optimal cutting parameters.

\section{Acknowledgments}

The authors would like to thank the Belgian National Fund for Scientific Research (NFSR-FRIA) for the financial support and the CNC Solutions - VDS company for the access granting to their machining robot.

\section{References}

[1] Pan, Z.; Zhang, H.; Zhu, Z. \& Wang, J. (2006). Chatter analysis of robotic machining process, Journal of Materials Processing Technology, Elsevier, vol. 173, pp. 301-309, doi:10.1016/j.jmatprotec.2005.11.033.

[2] Barnfather, J. D.; Goodfellow M. J. \& Abram T. (2016). A performance evaluation methodology for robotic machine tools used in large volume manufacturing, Robotics and Computer-Integrated Manufacturing, Vol. 37, pp. 49-56 from: http://dx.doi.org/10.1016/j.rcim.2015.06.002.

[3] Dumas, C.; Caro, S.; Garnier, S. \& Furet, B. (2011). Joint stiffness identification of six-revolute industrial serial robots, Robot. Comput. Integr. Manuf., Vol. 27(4), pp. 881-888, http://dx.doi.org/10.1016/j.rcim.2011.02.003.

[4] Weill, R. \& Shani, B. (1991). Assessment of accuracy in relation with geometrical tolerances in robot links. CIRP Ann. Manuf. Technol, Vol. 40, pp. 395-399, http://dx.doi.org/10.1016/S0007-8506(07)62015-0.

[5] Turek, P.; Jedrzejewski, J \& Modrzycki, W. (2010). Methods of machine tool error compensation, J. mach. Eng. Vol. 10 (4), pp.5-25, doi: 10.1016/j.procir.2013.06.078.

[6] Iglesias, I.; Sebastian, M. A., Ares, J. E. (2015). Overview of the state of robotic machining: current situation and future potential, Procedia Engineering, Vol. 132, pp. 911-917, doi: 10.1016/j.proeng.2015.12.577.

[7] Ilyukhin, Yu. V.; Poduraev, Yu. V.; Tatarintseva, A. V. (2014). Nonlinear adaptive correction of continuous path speed of the tool for high efficiency robotic machining, 25th DAAAM International Symposium on Intelligent Manufacturing and Automation, Procedia Engineering: Vol. 100, pp. 994-1002.

[8] Klimchik, A.; Ambiehl, A.; Garnier, S.; Furet, B. \& Pashkevich A. (2017). Efficiency evaluation of robots in machining applications using industrial performance measure, Robotics and Computer - Integrated Manufacturing, Vol. 48, pp. 12-29.

[9] Bauer, J.; Friedmann, M.; Hemker, T.; Pischan, M.; Reinl, C.; Abele \& von Stryk, O. (2013). Analysis of industrial robot structure and milling process Interaction for path manipulation (chapter 11), Process Machine Interactions, Springer, ISSN 2194-0525, DOI 10.1007/978-3-642-32448-2.

[10] Verlinden, O.; Ben Fékih, L. \& Kouroussis, G. (2013). Symbolic generation of the kinematics of multibody systems in EasyDyn: From MuPAD to Xcas/Giac, Theoretical and Applied Mechanics Letters, Vol. 3 (1), pp. 013012, doi: $10.1063 / 2.13013012$.

[11] Oueslati, M. (2013). Contribution à la modélisation dynamique, l'identification et la synthèse de lois de commande adaptées aux axes flexibles d'un robot industriel (translated: contribution to the dynamic modelling, the identification and the synthesis of command laws adapted for industrial robot flexible joints) (PhD thesis), L'école National Supérieure d'Arts et Métiers, Arts et Métiers ParisTech - Centre de Lille.

[12] Rivière-Lorphèvre, E.; Filippi, E. \& Dehombreux, P. (2007). Chatter prediction using dynamic simulation, International review of mechanical engineering (I.R.E.M.E.), Vol. 1, pp. 78-86.

[13] Tlusty, J. \& Polacek, M. (1963). The stability of the machine tool against self-excited vibration in machining, ASME International Research in Production Engineering, pp. 465-474.

[14] Peigné, G.; Paris, H. \& Brissaud, D. (2003). A model of milled surface generation for time domain simulation of high-speed cutting, Proceedings of the Institution of Mechanical Engineers, Vol. 217, pp. 919-930.

[15] Altintas, Y. \& Lee, P. (1996). A general mechanics and dynamics model for helical end mills, CIRP Annals Manufacturing Technology, Vol. 45, pp. 59-64, doi: 10.1016/S0007-8506(07)63017-0.

[16] Rivière-Lorphèvre, E.; Letot, C.; Ducobu, F.; Dehombreux, P. \& Filippi, E. (2017). Dynamic simulation of milling operations with small diameter milling cutters: effect of material heterogeneity on the cutting force model, Meccanica, Vol. 52, pp. 35-44.

[17] Huynh, H.N.; Rivière-Lorphèvre, E.; Verlinden, O. (2016). Integration of machining simulation within a multibody framework: application to milling, IMSD: The 4th Joint International Conference on Multibody System Dynamics.

[18] Huynh, H.N.; Rivière-Lorphèvre, E. \& Verlinden, O. (2016). Milling simulations with a 3-DOF flexible planar robot, World Academy of Science, Engineering and Technology, International Journal of Mechanical, Aerospace, Industrial, Mechatronic and Manufacturing Engineering, Vol. 10 (9), pp. 1647-1656. 